\title{
Success and Challenges in MOOCs: A Literature Systematic Review Technique
}

\author{
Wirapong Chansanam ${ }^{1}$, Kornwipa Poonpon ${ }^{1}$, Theeradej Manakul ${ }^{1}$, \\ Umawadee Detthamrong ${ }^{2}$ \\ ${ }^{1}$ Faculty of Humanities and Social Sciences, Khon Kaen University, Khon Kaen, Thailand \\ ${ }^{2}$ Chaiyaphum Business School, Chaiyaphum Rajabhat University, Chaiyaphum, Thailand
}

\begin{abstract}
The rapid evolution of massive open online courses (MOOCs) has attracted widespread media coverage to the propensity of conventional education methods to disrupt readily available and free or cheap content delivery. MOOCs enable the possibility to offer students, even throughout the leastserved parts of the globe, access to high-quality learning. MOOCs are progressively seen as a possibility for millions worldwide who want free or low-cost educational opportunities. The students just required a well-established internet connection to register for MOOCs. However, at the same time, Where MOOCs have such options of openness and flexibility, there are some challenges to MOOCs that are present as well. In this article, we have tried to examine all possible factors contributing to MOOCs and learners as a success, along with the challenges faced by MOOCs.
\end{abstract}

Keywords -Massive open online courses (MOOCs), Success, Challenge, Factors, Learning

\section{Introduction}

Nowadays, education systems are accessible to numerous population groups who were unable to join universities because of different factors [1].

DOI: $10.18421 /$ TEM104-32

https://doi.org/10.18421/TEM104-32

Corresponding author: Umawadee Detthamrong, Chaiyaphum Business School, Chaiyaphum Rajabhat University, Chaiyaphum, Thailand.

Email: umawadee.d@cpru.ac.th

Received: 10 June 2021.

Revised: 24 October 2021.

Accepted: 29 October 2021.

Published: 26 November 2021.

(c) BY-NC-ND C 2021 Wirapong Chansanam et al; published by UIKTEN. This work is licensed under the Creative Commons Attribution-NonCommercial-NoDerivs 4.0 License.

The article is published with Open Access at www.temjournal.com
In 2008, a concept was known as "MOOCs" launched a new wealth of perspectives for various, but this does not hold back at definitions or concepts, and it has also reinvigorated the global educational community because of its flexibility and openness. MOOCs are anticipated to swiftly replace the existing system of education with openness and scalability.

In 2012-2013, a massive open online course (MOOC) flourished. It is recognized worldwide by universities. Top organizations and universities, such as Harvard, Massachusetts Institute of Technology (MIT), and Stanford, began offering open and free courses online [2].

Different ideologies guide MOOCs in two different pedagogies, connectivity MOOCs (cMOOCs) based on informally developed connectivity theory and content-based MOOCs (xMOOCs), following a more behavioral approach [3].

In the traditional education system, where students have to face financial pressure, in MOOCs, students did not need a substantial budget to pay universities' fees and meet a strict timetable. MOOCs can provide, many students from all around the world, learning opportunities as long as it is connected to the course via the Internet [3]. Using the Internet, students can access educational material easily from their houses. However, if the living environment has no study space or the technology required to access the content is not accessible or distributed, it does not help the students [1].

There are several specific influences like the Internet that relate to the success of MOOCs, as well as some which pose as a barrier on MOOCs' path. The objective of this paper is to explore those factors which are contributing as a barrier/challenge in the implementation of MOOC's along with the factors which are contributing towards the success of MOOCs by reviewing the vast available literature between 2015 and 2020 from different databases. 


\section{Literature Review}

The advancement of new technologies and progressive social change has improved data production and sharing approaches, including simpler and greater access to information, mainly information services [4]. Modern technology enables enormous amounts of information from several domains to be gathered and processed. Web-based learning received considerable attention as it allows multiple media to be used for educational purposes. The first MOOC was started and made available in 2008. The course named Connectivism and Connective Knowledge course by Siemens and Downes in 2008 was offered, and 2200 learners signed up for this course [5]. Since then, the different companies and universities started to publish their own MOOCs like Coursera, Udacity, Khan Academy. It is reasonable for the pedagogical vectors of positive personal growth that are in high demand in the contemporary digital market [6]. The New York Times also label the year 2012 as "the year of the MOOC" [7]. Figure 1 demonstrates how the transition starts in the MOOC and the trends upwards by the end of 2012 because of various organizations' contribution to the MOOCs.

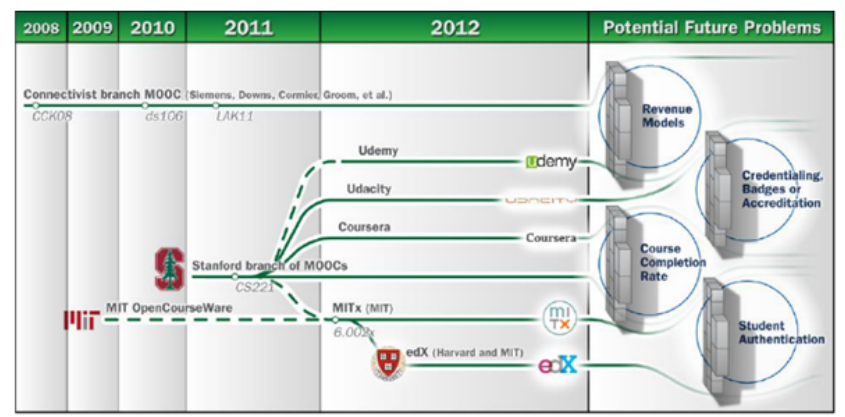

Figure 1. History of MOOCs Source Hill (2014)

Figure 2 below shows the growth of the MOOC, indicating a large upward graph from the end of 2012. The main aim was to replace the conventional education system and provide the know-how for those students who could not attend the training institutions such as colleges and universities.

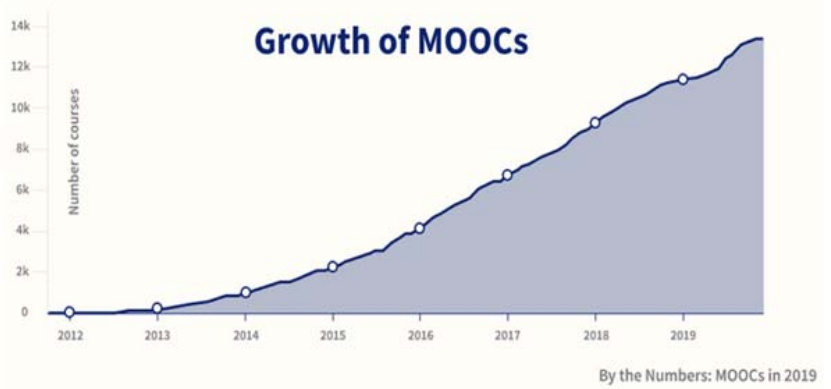

Figure 2. Growth of MOOCs, Source: by the Numbers:MOOCs in 2019 by Dhawal Shah, https://www.classcentral.com/report/mooc-stats-2019

\section{cMOOCs and $x$ MOOCs}

Since MOOCs have expanded and implemented new technologies and concepts, unlike the first MOOC, which was cMOOCs and is based on connectivity theory in which students get to choose which skills they want to learn. Knowledge and contents are produced by students and are also given by students in cMOOCs. As shown in the below Figure 3 in cMOOCs, every participant ' $\mathrm{P}$ ' is sharing resources ' $R$ ' with every other participant. Every ' $P$ ' is the origin of information that is accessible by all other 'P's.

In 2012-2013, xMOOCs were introduced, which flourished due to their high acceptance rate based upon behavioral theory, as mentioned previously.

xMOOCs are based on recorded video, automated feedback, and other lecture contents referred to as resources. The resources ' $\mathrm{R}$ ' in xMOOC is then shared with all participants on a single platform, "P." However, the participants do not share any resources on the platform. The only origin of resources in $\mathrm{xMOOc}$ is indeed the instructor/teacher. The whole session is split into various divisions in order to prevent misunderstanding and linearly follow the course, as shown in Figure 4.

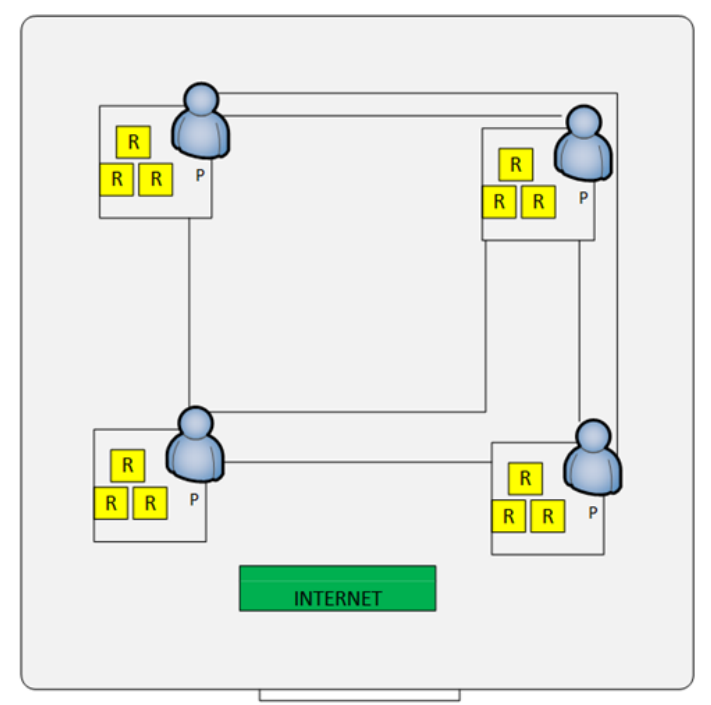

Figure 3. cMOOCs structure

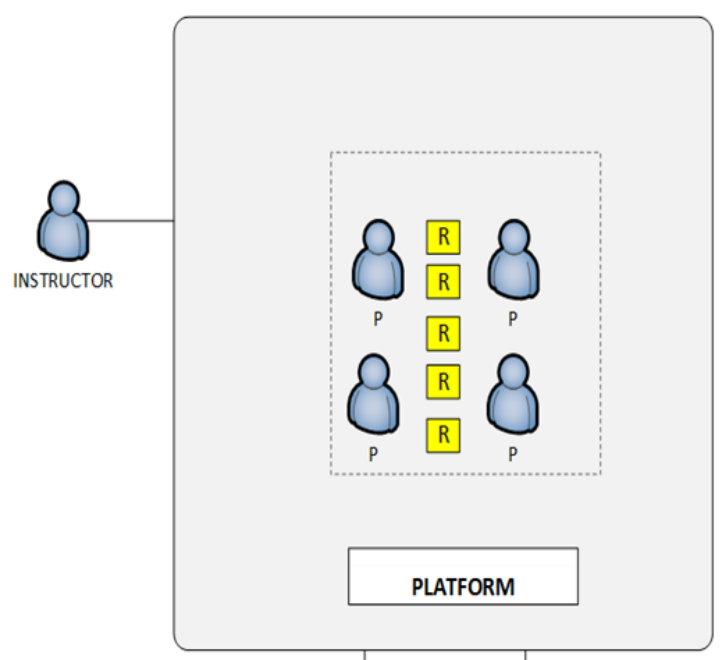

Figure 4. xMOOCs structure 


\section{Research Methodology}

\subsection{Research Questions}

- What are the different factors that contribute to the success of MOOCs?

- Which are also the challenges facing MOOCs presently?

- What are the different suggestions for the success of MOOCs that can be made upon the basis of literature?

\subsection{Data Collection}

The topics are described from the previous studies and remain focused chiefly on developments of MOOCs education-related, based on the previous five years (2015-2020) and improving conceptual knowledge of the literature concerned. This empirical research examined and analyzed is not comprehensive, but it is focused on relevance, and the primary goal of this research is to identify success factors contributing to MOOCs' success along with the challenges. The method used in this research is to obtain data that is therefore not as rigorous and relevant as a systematic review of the literature since the identification of main topics is more important than the number of papers read related to the success of MOOCs.

\subsection{The Search Process}

The research was performed between the time of July 2019 and June 2020. Furthermore, the systematic literature search was performed to identify the factors considered successful factors for MOOCs published from 2015 to and up to March 2020. A specific keyword query generally generates just so many links that have to be screened in addition [8]. The specific criteria for searching have been listed: 'MOOC,' 'Opportunities for MOOCs', 'Challenges to MOOCs', 'Factors influencing the MOOCs Success', 'Success of MOOCs', 'MOOC' or 'Massive Open Online Courses' in the search bar as the main title and 'impact' or 'successful' and between 2015 to 2020 the chosen years were in the report. If any of these individual searches returned more than 700 results, the search was performed again with an entry term (implementation) using the Boolean operator 'AND'. The analysis process was carried out personally, and a representative fraction of papers was chosen, mainly because repetitive topics existed. The redundancy as far as feasible has been avoided. Due to the study's exploratory nature, the search was not intended to address all possible results. The search process is very much cleared and carried out by authors at a different time. The papers were selected from different resources by considering the main theme of this article. The search process has been followed shown in Figure 5 below:

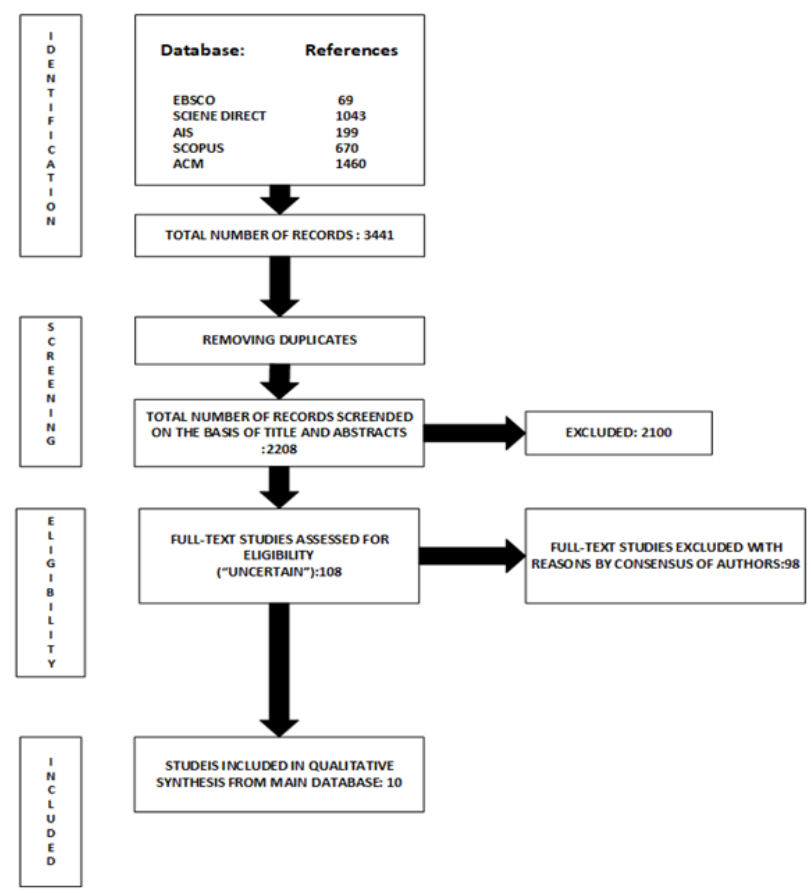

Figure 5. Flow diagram showing the different stages of systematic literature review

\section{Results}

From the criteria that have been specified in Figure 1 , the results are showing in Table 1 below. The Table showing the following information

- The Authors

- The factors required for the success of MOOCs

To summarize, a total of twenty-three factors identified from the systematic literature review that contribute to the success of MOOCs are presented in Table 1. The factors contributing towards the success of MOOCs are Timing [18], Quality Resources [9], [18], Interactivity and Peer-to-Peer Pedagogy [10], [15], [18], Content Organisation and Access [18], System Quality [9], Perceived ease of use [9], Perceived usefulness [9], Game-based or gamification elements [10], [14], [16], Quizzes and immediate feedback [10], [15], Correct difficulty level [10], Real-world challenges and testing [10], Start date [17], Direct communication [15], MOOCs gives anyone access [11], Prior knowledge [12], Understand Material [13], New Knowledge [13], New Resources to use [13], Enjoyment [13], Recognition [13], Expanded world view [13], Skills [12], and Use of Social Media in education [13]. The factors with checkbox "Tick" against the authors show that they have mentioned these factors as a success contributor; however, the boxes with "Cross" represent that the authors did not mention these factors in their research work. 
Table 1. Factors contributing towards the success of MOOCs

\begin{tabular}{|c|c|c|c|c|c|c|c|c|c|c|}
\hline Factors & & & & & Aut & hors & & & & \\
\hline & [9] & [10] & [11] & [12] & [13] & [14] & [15] & [16] & [17] & [18] \\
\hline Timing & $\sqrt{x}$ & $x_{x}^{x}$ & $x_{x}^{x}$ & $x_{x}^{x}$ & $x_{x}^{x}$ & $x_{x}^{x}$ & $x_{x}^{x}$ & $x^{x}$ & $x$ & 2 \\
\hline $\begin{array}{l}\text { Quality Resources } \\
\text { Interactivity and Peer-to-Peer Pedagogy }\end{array}$ & $\times$ & $\underline{x}$ & $\begin{array}{l}x \\
x\end{array}$ & $\begin{array}{l}x \\
x\end{array}$ & $\begin{array}{l}x \\
x\end{array}$ & $\begin{array}{l}x \\
x\end{array}$ & $x^{x}$ & $\begin{array}{l}x \\
x\end{array}$ & $\begin{array}{l}x \\
x\end{array}$ & \\
\hline Content Organisation and Access & $x$ & $\times$ & $\hat{x}$ & $\hat{x}$ & $\hat{x}$ & $\hat{x}$ & $\times$ & $\hat{x}$ & $\hat{x}$ & 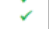 \\
\hline System Quality & $\checkmark$ & $\times$ & $\times$ & x & $x$ & $\times$ & $\times$ & $\times$ & $\times$ & $x$ \\
\hline Perceived ease of use & $\checkmark$ & $\times$ & x & $x$ & $x$ & * & * & $\times$ & $\times$ & \\
\hline Perceived usefulness & $\checkmark$ & $\times$ & $x$ & $\times$ & x & x & $\times$ & $\times$ & $\times$ & \\
\hline Game-based or gamification elements & $x$ & $\checkmark$ & x & $\times$ & x & $\checkmark$ & × & $\checkmark$ & × & \\
\hline Quizzes and immediate feedback & * & $\checkmark$ & × & x & x & × & $\checkmark$ & $\times$ & x & \\
\hline Correct difficulty level & x & $\checkmark$ & 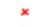 & $\times$ & $x$ & * & $\times$ & $x$ & $x$ & \\
\hline Real world challenges and testing & $x^{x}$ & 2 & $x^{x}$ & $x^{2}$ & $x$ & 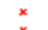 & ${ }^{x}$ & $x^{x}$ & $x$ & * \\
\hline Start date & $x$ & $x$ & $x$ & $x$ & $x$ & * & $\times$ & $x$ & $\checkmark$ & \\
\hline Direct communication & $x^{x}$ & $x^{x}$ & $x$ & $\times$ & $x^{x}$ & $x^{x}$ & s & $x^{x}$ & $x^{x}$ & \\
\hline MOOCs gives anyone access & $x$ & $x$ & $\checkmark$ & $x$ & $\times$ & * & * & $x$ & $x$ & \\
\hline $\begin{array}{l}\text { Prior knowledge } \\
\text { Pnone access }\end{array}$ & $x$ & $\times$ & $x$ & $\checkmark$ & $x$ & $\times$ & $\times$ & $x^{x}$ & ${ }^{x}$ & \\
\hline Understand Material & $x^{x}$ & $x^{x}$ & $*$ & $x^{x}$ & 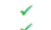 & $x^{x}$ & $x^{x}$ & $x$ & $x^{x}$ & $x$ \\
\hline New Knowledge & $x^{x}$ & $x^{x}$ & $\stackrel{x}{x}$ & $x^{x}$ & 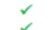 & $\stackrel{x}{x}$ & $\stackrel{x}{x}$ & $x^{x}$ & $\stackrel{x}{x}$ & \\
\hline New Resources to use & ${ }^{x}$ & ${ }^{x}$ & ${ }^{x}$ & $x^{x}$ & s & $\stackrel{x}{x}$ & $\stackrel{x}{x}$ & $\stackrel{x}{x}$ & $\stackrel{x}{x}$ & \\
\hline Enjoyment & $\stackrel{x}{x}$ & $\stackrel{x}{x}$ & $\stackrel{x}{x}$ & $\stackrel{x}{x}$ & 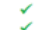 & $\stackrel{x}{x}$ & $\stackrel{x}{x}$ & $\stackrel{x}{x}$ & $\stackrel{x}{x}$ & 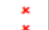 \\
\hline Recognition & $\stackrel{x}{x}$ & $x_{x}$ & $\begin{array}{l}x \\
x\end{array}$ & $x^{x}$ & 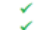 & $x_{x}^{x}$ & $x_{x}^{x}$ & $\stackrel{x}{x}$ & $\stackrel{x}{x}$ & $x_{x}^{x}$ \\
\hline $\begin{array}{l}\text { Expanded world view } \\
\text { Skikd }\end{array}$ & $x_{x}$ & $x_{x}$ & $\begin{array}{l}x \\
x\end{array}$ & $x^{x}$ & x & $\begin{array}{l}x \\
x\end{array}$ & $\begin{array}{l}x \\
x\end{array}$ & $\stackrel{x}{x}$ & $\begin{array}{l}x \\
x\end{array}$ & $\begin{array}{l}x \\
x\end{array}$ \\
\hline $\begin{array}{l}\text { Skills } \\
\text { Use of Social Media in education }\end{array}$ & $\begin{array}{l}x \\
x\end{array}$ & $\begin{array}{l}x \\
x\end{array}$ & $\hat{x}$ & $x$ & $\stackrel{x}{r}$ & $\begin{array}{l}x \\
x\end{array}$ & ${ }_{x}^{*}$ & $\begin{array}{l}x \\
x\end{array}$ & $\begin{array}{l}x \\
x\end{array}$ & ${ }_{x}^{x}$ \\
\hline
\end{tabular}

However, it is notable that there are very few factors that are mentioned by more than in two studies. Gamification is identified by three times in literature and it is the only factor in this empirical study of set of articles who have occurrence of 3 times, none of any other factors were mentioned like gamification along with Interactivity which is also mentioned three times. So, upon the base of previous studies it can be said that gamification and interactivity is an important element in MOOCs who have considerable attention by different researchers.

Likewise, quality resources and immediate feedback are another two more important factors of MOOCs success after gamification and interactivity. The two resources mentioned above also gained the significant attention of a researcher, and all other elements mentioned in Table 1 are only mentioned by a researcher in their own research according to this study, as well as skills, prior knowledge, system quality etc.

In Table 2, fifteen factors ought to be a challenge for MOOCs' success mentioned in the literature system review. The factors related to MOOCs as challenges are Difficulty level not aligned to the skills of the student [10], Unengaged students [10], [13], No accreditation [10], Ineffective assessment and limited feedback [10], Lack of interactivity of the course offering [10], No peer or tutorial support [10], Peer grading for assessments [17], Long course length [17], Lack of Internet access is a barrier [11], the quality of MOOCs are questionable [11], Lack of basic knowledge is a barrier [11], Level of education is a barrier [11], Frequent MOOCing [13], Life Circumstances [13], and No investment [13]. Furthermore, some authors [12], [14], [15], [16], [18] have not mentioned. However, the unengaged students are the only challenges mentioned in two researchers [10], [13]. Except this, all fourteen other factors that are a barrier to MOOCs' success are only mentioned once, which required more research to understand. Therefore, if the challenges mentioned will be avoided and the success factors mentioned in Table 1 added to MOOCs, it can mean that MOOCs' success will have a great opportunity to reduce the main problem of 'drop out' many students joined MOOCs. However, they cannot carry on as the course progresses; the ratio of the present student or enrolled students starts to decrease. Hence, this paper can provide guidelines to MOOCs providers that can make the success of MOOCs.

Table 2. Factors associated with MOOCs as challenges

\begin{tabular}{|c|c|c|c|c|c|c|c|c|c|c|}
\hline \multirow[t]{2}{*}{ Factors } & \multicolumn{10}{|c|}{ Authors } \\
\hline & [9] & {$[10]$} & [11] & [12] & [13] & [14] & [15] & [16] & [17] & [18] \\
\hline $\begin{array}{l}\text { Difficulty level not aligned to the skills } \\
\text { of the student }\end{array}$ & $x$ & & $x$ & $x$ & $x$ & $x^{2}$ & $x^{2}$ & $x^{2}$ & $x$ & \\
\hline Unengaged students & $x$ & $\checkmark$ & $\mathbf{x}$ & $x$ & $\checkmark$ & $\mathbf{x}$ & $\times$ & $x$ & $x$ & $x$ \\
\hline No accreditation & $\times$ & 2 & $\times$ & $x$ & $\times$ & $\times$ & $\times$ & $x$ & $\times$ & $\times$ \\
\hline $\begin{array}{l}\text { Ineffective assessment and limited } \\
\text { feedback }\end{array}$ & $x$ & $\checkmark$ & $\times$ & $x$ & $x$ & $x$ & $\mathbf{x}$ & $x$ & 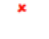 & $\times$ \\
\hline $\begin{array}{l}\text { Lack of interactivity of the course } \\
\text { offering }\end{array}$ & $\times$ & $\checkmark$ & $x$ & x & $\times$ & $\times$ & $x$ & $x$ & 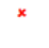 & $\times$ \\
\hline No peer or tutorial support & $x$ & $\checkmark$ & $x$ & $\mathbf{x}$ & $\mathbf{x}$ & $\times$ & $x$ & $x$ & $\mathbf{x}$ & $x$ \\
\hline Peer grading for assessments & $x$ & $\times$ & $x$ & 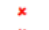 & $x$ & $x$ & $x$ & $x$ & $\checkmark$ & $\times$ \\
\hline Long course length & $\mathbf{x}$ & $x$ & $x$ & $\mathbf{x}$ & $x$ & $\mathbf{x}$ & $x$ & $x$ & $\checkmark$ & $\times$ \\
\hline Lack of Internet access is a barrier & 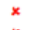 & $\times$ & $\checkmark$ & $x$ & 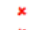 & $x$ & $x$ & $x$ & $x$ & $\times$ \\
\hline The quality of MOOCs are questionable & $\times$ & $\times$ & $\checkmark$ & $\mathbf{x}$ & $x$ & $\mathbf{x}$ & $x$ & $x$ & $x$ & $\times$ \\
\hline Lack of basic knowledge is a barrier & $\mathbf{x}$ & $\times$ & $\checkmark$ & $\mathbf{x}$ & $x$ & $\times$ & $x$ & $\times$ & x & $x$ \\
\hline Level of education is a barrier & $\mathbf{x}$ & $x$ & $\checkmark$ & $\times$ & $x$ & $x$ & $x$ & $\times$ & 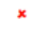 & $\times$ \\
\hline Frequent MOOCing & $x$ & $x$ & $x$ & $x$ & $\checkmark$ & $\mathbf{x}$ & $x$ & $x$ & $x$ & $\times$ \\
\hline Life Circumstances & $x$ & $\times$ & $x$ & $x$ & $\checkmark$ & $\mathbf{x}$ & $\times$ & $x$ & $x$ & $\times$ \\
\hline No investment & $x$ & $\mathbf{x}$ & $\mathbf{x}$ & $x$ & $\checkmark$ & $x$ & 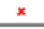 & $x$ & $\mathbf{x}$ & $x$ \\
\hline
\end{tabular}

\section{Conclusion and Future Work}

As seen, MOOC has gained enough attention globally, either in terms of academia or economics. Many top-class institutes are providing MOOCs today, like Harvard, MIT, etc. Since the launch of MOOCs, it is progressing. However, at the same time, there are some challenges to MOOCs as well by which these articles provide an opportunity to identify elements that are contributing toward the success of MOOCs not only to identify but will also help to sum up these elements which could help the MOOC or instructional designer to provide the best quality MOOCs. Since every previous re-search has its direction and except gamification and interactivity, no other elements are even mentioned as success in MOOCs in previous studies between 2015-2020. This study can help different researchers in the future explore more about other elements other than mentioned above in Table 1 and Table 2.

It can also be suggested upon the basis of literature that there are very few elements related to technology in previous studies as MOOCs are web-based, and the Internet is considered a backbone of MOOCs. So, in the future, more technological factors associated with MOOCs will be studied comprehensively, which will help design the framework for MOOCs in the future.

Similarly, the MOOCs is all about learning and providing training, so it is also essential to study those factors, including those who can help the learners to en-gage in their learning because MOOCs' biggest issue is dropout many learners joined MOOCs, but as furthered course progress the ratio of learner starts decreasing. 


\section{References}

[1]. Liyanagunawardena, T. R. (2012). Information communication technologies and distance education in Sri Lanka: A case study of two universities. (Doctoral dissertation, University of Reading).

[2]. Ayub, E., \& Leong, L. C. (2017). Developing a pedagogy framework for institution-wide implementation of MOOC: A case study from a Malaysian Private University. Advanced Science Letters, 23(2), 809-813.

[3]. Collazos, C. A., González, C. S., \& García, R. (2014, June). Computer supported collaborative MOOCs: CSCM. In Proceedings of the 2014 Workshop on Interaction Design in Educational Environments (pp. 28-32).

[4]. Chansanam, W., Tuamsuk, K., \& Chaikhambung, J. (2020). Linked Open Data Framework for Ethnic Groups in Thailand Learning. International Journal of Emerging Technologies in Learning (iJET), 15(10), 140-156. https://doi.org/10.3991/ijet.v15i10.13337

[5]. Fini, A. (2009). The technological dimension of a massive open online course: The case of the CCK08 course tools. International Review of Research in Open and Distributed Learning, 10(5).

[6]. Zotova, M., Likhouzova, T., Shegai, L., \& Korobeynikova, E. (2021). The Use of MOOCS in Online Engineering Education. International Journal of Engineering Pedagogy, 11(3). https://doi.org/10.3991/ijep.v11i3.20411

[7]. Chauhan, A. (2014). Massive open online courses (MOOCS): Emerging trends in assessment and accreditation. Digital Education Review, (25), 7-17.

[8]. Tuamsuk, K., Chansanam, W., \& Kaewboonma, N. (2018). Ontology of folktales in the Greater Mekong Subregion. International Journal of Metadata, Semantics and Ontologies, 13(1), 57-67. https://doi.org/10.1504/IJMSO.2018.096454

[9]. Yang, M., Shao, Z., Liu, Q., \& Liu, C. (2017). Understanding the quality factors that influence the continuance intention of students toward participation in MOOCs. Educational Technology Research and Development, 65(5), 1195-1214.
[10]. De Freitas, S. I., Morgan, J., \& Gibson, D. (2015). Will MOOCs transform learning and teaching in higher education? Engagement and course retention in online learning provision. British journal of educational technology, 46(3), 455-471. https://doi.org/10.1111/bjet.12268

[11]. Semenova, T. V., \& Rudakova, L. M. (2016). Barriers to taking massive open online courses (MOOCs). Russian Education \& Society, 58(3), 228245. https://doi.org/10.1080/10609393.2016.1242992

[12]. Kennedy, G., Coffrin, C., De Barba, P., \& Corrin, L. (2015, March). Predicting success: how learners' prior knowledge, skills and activities predict MOOC performance. In Proceedings of the fifth international conference on learning analytics and knowledge (pp. 136-140). https://doi.org/10.1145/2723576.2723593

[13]. Loizzo, J., Ertmer, P. A., Watson, W. R., \& Watson, S. L. (2017). Adult MOOC Learners as Self-Directed: Perceptions of Motivation, Success, and Completion. Online Learning, 21(2), n2. https://doi.org/10.24059/olj.v21i2.889

[14]. Gené, O. B., Martinez-Nuñez, M., \& Blanco, A. F. (2016). New challenges for the motivation and learning in engineering education using gamification in MOOC. The International journal of engineering education, 32(1), 501-512.

[15]. Krusche, S., \& Seitz, A. (2019, January). Increasing the interactivity in software engineering moocs-a case study. In Proceedings of the 52nd Hawaii International Conference on System Sciences.

[16]. Aparicio, M., Oliveira, T., Bacao, F., \& Painho, M. (2019). Gamification: A key determinant of massive open online course (MOOC) success. Information \& Management, 56(1), 39-54.

https://doi.org/10.1016/j.im.2018.06.003

[17]. Jordan, K. (2015). Massive open online course completion rates revisited: Assessment, length and attrition. International Review of Research in Open and Distributed Learning, 16(3), 341-358. https://doi.org/10.19173/irrodl.v16i3.2112

[18]. Azevedo, J., \& Marques, M. M. (2017). MOOC Success Factors: Proposal of an Analysis Framework. Journal of Information Technology Education: Innovations in Practice, 16, 233-251. 